\title{
Tachistoscopic recognition thresholds and meaningfulness
}

WALTER SCHUTTE AND NEIL HILDEBRAND

UNIVERSITY OF MANITOBA, WINNIPEG, CANADA

An inverse relationship between tachistoscopic recognition thresholds and meaningfulness (M) of nonsense syllables was demonstrated. The failure of previous studies to employ $M$ measures standardized on the population under study and the procedure of pre-exposing test lists to $S$ s were suggested as reasons for the failure of previous studies to demonstrate the phenomenon.

An inverse relationship between the tachistoscopic recognition threshold of a word and its frequency of occurrence in written language has been consistently demonstrated (e.g., Howes \& Solomon, 1951; Postman, 1953). The same inverse relationship has also been demonstrated between prior usage of nonsense words and their recognition thresholds (e.g., Solomon \& Postman, 1952; Postman \& Rosenzweig, 1956). These findings suggest that verbal stimuli which Ss have experienced more frequently are more rapidly recognized than verbal stimuli with which they have had less experience.

Frequency of experience has been postulated as an important antecedent condition determining the meaningfulness (M) of verbal stimuli (Underwood \& Schultz, 1960). If frequency of experience is a determinant of $M$, and since tachistoscopic recognition thresholds are inversely related to frequency of experience, then tachistoscopic recognition thresholds should also be inversely related to $M$. Such a relationship has been demonstrated for words (Kristofferson, 1957), but attempts using nonsense syllables have been unsuccessful (Taylor, 1958; Gibson, Bishop, Schiff, \& Smith, 1964; Koplin \& Spielberger, 1964; Winnick \& Ellner, 1965).

Common to all the unsuccessful studies were one or both of two methodological errors, viz., failure to obtain $M$ measures for the nonsense syllables from the same population used in testing and pre-exposure of test lists to Ss. Most studies used either the Glaze or Noble M values for nonsense syllables. Assumptions that these values may be generalized to populations which are geographically or temporally distant from those used by Glaze or Noble were unwarranted. Preexposure of the test list may provide Ss with a set of cues for recognition of a syllable different from three letters in a given order, viz., the overall shape or silhouette of the syllable.

The purpose of this study was to investigate the relationship between recognition thresholds and M using nonsense syllables with $M$ values assigned by the population being tested. It was hypothesized that thresholds would vary inversely with $M$.

\section{Method}

Subjects. Ss were 13 male and female college students with no reported visual defects and no prior experience with nonsense syllables.

Stimuli. The stimuli were $20 \mathrm{CVC}$ trigrams selected from a list of 60 nonsense syllables which were randomly selected from the Glaze list in Underwood \& Schultz (1960). The $60 \mathrm{CVC}$ trigrams were rated for $M$ by the association production method (number of associations to a stimulus syllable in $30 \mathrm{sec}$.) on 50 Ss from the same subject pool used in the present study. Ten syllables with the highest $M$ values were denoted the high-M group, and the 10 with the lowest values, the low-M group. The syllables were presented in a different random order to each $S$.

Procedure. Ss were tested individually, while seated before a modified American Optical Root Nearpoint tachistoscope, Model 1340. The modification consisted of replacement of the original light source and shutter system with a neon-argon flash tube array pulsed by a Hunter Model $100 \mathrm{C}$ series D decade interval timer. The exposure interval was measured by a Hunter Model $120 \mathrm{~K}$ series $\mathrm{D}$ Klockounter. The duration of exposure was increased in $.01 \mathrm{sec}$. steps, from .01 sec., with the presentation at each level until the stimulus was recognized. Ss were required to spell out the syllable and encouraged to guess. If they did not see the entire syllable they were asked to report individual letters. The criterion of recognition was one correct report of the stimulus. The dependent variable was the interval of exposure at the time $\mathrm{S}$ made a correct report. The CVC trigrams were presented

Table 1. Mean Recognition Threshold Duration for 10 High- and 10 Low-Meaningful Nonsense Syllables

\begin{tabular}{ccc} 
Subject & $\begin{array}{c}\text { Mean Low M } \\
\text { Seconds }\end{array}$ & $\begin{array}{c}\text { Mean High M } \\
\text { Seconds }\end{array}$ \\
\hline 1 & .0654 & .0675 \\
2 & .0276 & .0232 \\
3 & .0421 & .0358 \\
4 & .0864 & .0562 \\
5 & .0965 & .0511 \\
6 & .0931 & .0837 \\
7 & .0323 & .0424 \\
8 & .0435 & .0320 \\
9 & .1114 & .0741 \\
10 & .1180 & .0717 \\
11 & .2123 & .1793 \\
12 & .0560 & .0346 \\
13 & .0357 & .0339 \\
\hline
\end{tabular}


without pre-exposure of the list or practice on the tachistoscope aside from having $\mathrm{S}$ report seeing the fixation point in the apparatus.

\section{Results and Discussion}

The mean threshold exposure duration times of each $\mathrm{S}$ for high $\mathrm{M}$ and low $\mathrm{M}$ nonsense syllables are presented in Table 1. The analysis of variance (Lindquist, 1953, Treatments by Subjects design) confirmed the prediction that recognition thresholds are inversely related to $M$. The main effect for meaningfulness $(F=8.38$, $\mathrm{df}=1 / 12)$ and the main effect for $\mathrm{Ss}(\mathrm{F}=19.34$, $\mathrm{df}=$ $12 / 12)$ were both statistically significant.

The results of this study support the hypothesis that recognition thresholds vary inversely with $M$. Furthermore, it would appear that standardization of $M$ measures on the population from which the sample is drawn and no prior exposure of the lists may be critical methodological procedures in studies involving nonsense syllable recognition thresholds and meaningfulness.

\section{References}

Gibson, E. J., Bishop, C. H., Schiff, W., \& Smith, J. Comparison of meaningfulness and pronouncability as grouping principles in the perception and retention of verbal material. J. exp. Psychol., 1964, 67, 178-182.

Howes, D. H., \& Solomon, R. L. Visual duration threshold as a function of word probability. J. exp. Psychol., 1951, 41, 401-410.

Koplin, J. H., \& Spielberger, C. D. Meaningfulness and visual recognition threshold. Percept. mot. Skills, 1964, 19, 207-210.

Kristofferson, A. B. Word recognition, meaningfulness, and familiarity. Percept. mot. Skills, 1957, 7, 219-220.

Lindquist, E. F. Design and analysis of experiments. Boston: Houghton Mifflin, 1953.

Postman, L. The experimental analysis of motivational factors in perception. In M. R. Jones (Ed.), Current theory and research in motivation: a symposium. Lincoln: University of Nebraska Press, 1953. Pp. 59-108.

Solomon, R. L., \& Postman, L. Frequency of usage as a determinant of recognition thresholds for words. J. exp. Psychol., $1952,43,195-201$.

Taylor, J. A. Meaning, frequency, and visual duration threshold. J. exp. Psychol., 1958, 55, 329-334.

Underwood, B. J., \& Schultz, R. W. Meaningfulness and verbal learning. Chicago: Lippincott, 1960.

Winnick, W. A., \& Ellner, M. "Meaningfulness" in tachistoscopic thresholds, serial learning, and association measurement. Psychon. Sci., 1965, 2, 233-234. 